\title{
Memory enhancement of a partly-learned discrimination in pigeons by intramuscular injection of physostigmine*
}

\author{
G. B. BIEDERMAN \\ University of Toronto, Toronto, Ont., Canada
}

Pigeons, individually trained in two discrimination tasks, with one well learned and one partly learned, showed improvement in relearning each task following injection of the anticholinesterase physostigmine. A control group, receiving saline after 28 days had elapsed from the original training, showed forgetting of the partly learned discrimination. The 28-day physostigmine group showed improvement in the relearning of the partly learned discrimination. These facts suggest that anticholinesterase injection had facilitated the memory of the partly learned task in the experimental group. The failure of anticholinesterase to produce amnesia in pigeons, while apparently facilitating memory for a partly forgotten discrimination, suggests that pigeon memory may operate in a different temporal sequence than does rat memory.

Deutsch \& Leibowitz (1966) report that diisopropyl fluorophosphate (DFP), an anticholinesterase, produced recall of an almost forgotten task that had been learned by rats 28 days earlier. Amnesia was produced for a well remembered task, learned 14 days before, by injecting DFP, as in Deutsch, Hamburg, \& Dahl (1966). The injection had no effect on the recall of a habit partly learned 14 days earlier. Deutsch and Leibowitz used separate groups of rats trained either 14 or 28 days before injection of DFP. A group was either well or partly trained in a Y-maze situation, where selection of the lighted arm was rewarded by escape from shock. Deutsch interprets these data to support the hypothesis that learning consists of the modification of the nonfunctional synapse to produce transmitter. Newly modified synapses should be less affected by anticholinesterase, while transmitting synapses modified earlier should be blocked by anticholinesterase, since relatively more cholinesterase is present. If forgetting is the reduction of transmitter, anticholinesterase will presumably improve transmission by allowing acetylcholine to increase (Deutsch \& Leibowitz, 1966).

The purpose of the experiment reported here was to determine if the memory pattern Deutsch has described will occur when Ss serve as their own learning control in a within-Ss experimental design. Each $S$ is well trained on one task and partly trained on another (Biederman, 1968). Memory for each task may be evaluated after varying amounts of time have elapsed between the original training and injection of an anticholinesterase, in this case,

* Supported by Ontario Mental Health Foundation Grant 106 and Canadian National Research Council Grant 185. I thank G. A.J. Heighington for assistance in this experiment. physostigmine (Hamburg, 1967). The hypothesis suggested by Deutsch would predict that at certain training-injection intervals Ss should show amnesia for the well-learned task and memory enhancement of the partly learned discrimination.

Vaillant (1964) reports that pigeons suffer central effects from injection of physostigmine $(0.25 \mathrm{mg} / \mathrm{kg} \mathrm{IM})$. He also reports a suppression of operant responding (Vaillant, 1964, 1967) similar to that demonstrated in rats (Biederman, 1970); the pigeon, therefore, was selected for the complex training task that this experiment required (Biederman, 1968). SUBJECTS

Male Carneaux pigeons $(N=48)$ served

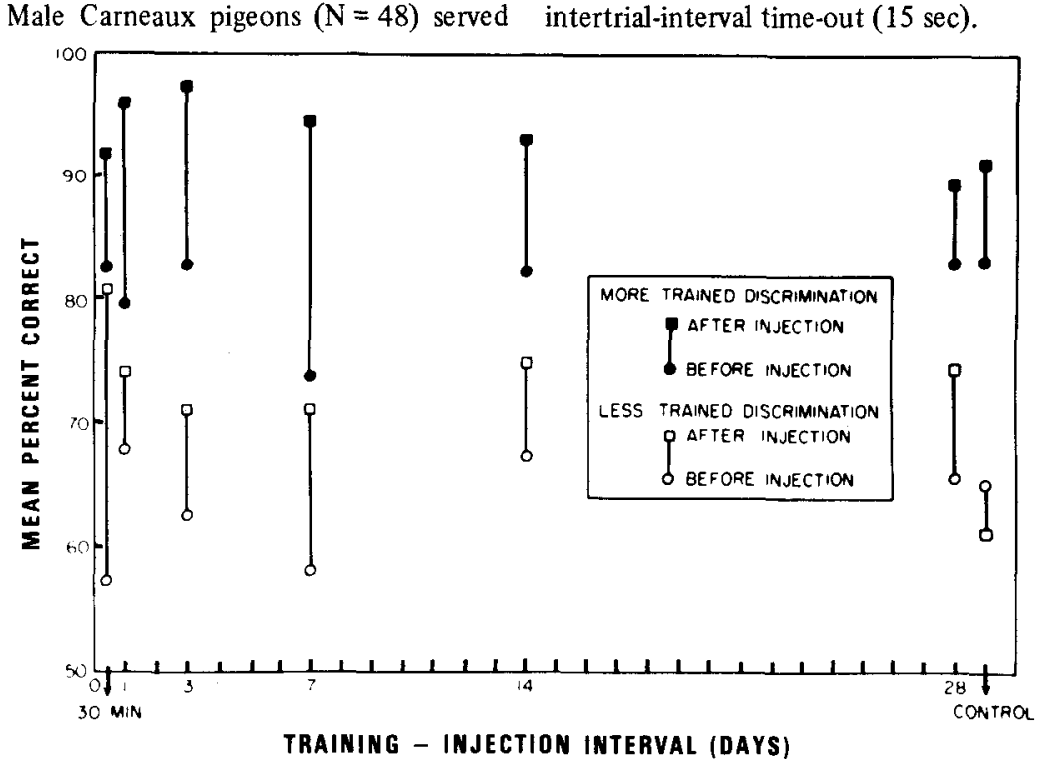

Fig. 1. Mean percent correct on more- and less-trained discriminations before and after injection of physostigmine as a function of the interval between training and injection. The control group received saline solution after 28 days had elapsed from the original learning. illuminated with white light that varied as Ss, maintained at $80 \%$ of free-feeding weight.

The experimental apparatus that has been described elsewhere (Biederman, 1968) consisted of two two-key experimental chambers (Grason-Stadler) with automatic programming and recording equipment. The response keys were lighted with color or figure stimuli. Shaping was accomplished in six one-key chambers with attendant automated apparatus. An $80-\mathrm{dB}$ white noise masked equipment noises.

\section{PROCEDURE}

The Ss were trained to peck a key illuminated with white light for a $2-\mathrm{sec}$ access to the grain magazine. After shaping, which terminated when 100 unassisted responses occurred, Ss were transferred on the following day to the two-key chambers, where side preference was eliminated by training Ss to peck the key semirandomly from side to side. Training consisted of Ss learning two simultaneous discriminations (red vs green and horizontal vs vertical lines) in a trial-by-trial procedure.

The red-green discrimination appeared twice as frequently as the horizontal-vertical task, which was intersticed randomly between red-green trials. In simultaneous discrimination the stimulus correlated with reward (the positive) or the stimulus correlated with nonreward (the negative) on any given trial. A 2-sec access to the food magazine followed a correct response, while an incorrect response resulted in an intertrial-interval time-out $(15 \mathrm{sec})$. 
Table 1

Comparisons Between Original Training and Retraining for Well $T$ rained and Partly Trained Discriminations After Physostigmine Injection

\begin{tabular}{cll}
$\begin{array}{c}\text { Training-Injection } \\
\text { Interval }\end{array}$ & $\begin{array}{c}\text { Red-Green } \\
\text { Discrimination }\end{array}$ & $\begin{array}{c}\text { Horizontal-Vertical } \\
\text { Discrimination }\end{array}$ \\
\hline 30 Min & $\mathrm{t}=3.70, \mathrm{p}<.02$ & $\mathrm{t}=3.46 . \mathrm{p}<.02$ \\
1 Day & $\mathrm{t}=3.21, \mathrm{p}<.05$ & $\mathrm{t}=0.70$ \\
3 Days & $\mathrm{t}=4.17, \mathrm{p}<.01$ & $\mathrm{t}=1.70$ \\
7 Days & $\mathrm{t}=2.33$ & $\mathrm{t}=2.67, \mathrm{p}<.05$ \\
14 Days & $\mathrm{t}=3.48, \mathrm{p}<.02$ & $\mathrm{t}=1.08$ \\
28 Days & $\mathrm{t}=1.73$ & $\mathrm{t}=1.44$ \\
\hline
\end{tabular}

Training proceeded in 150 trial blocks until Ss exceeded $90 \%$ correct on the more-trained color discrimination and $60 \%$ on the less-trained horizontal-vertical discrimination for the last block of 50 trials. Training was completed in a single day. Ss were then replaced in home cages for a variable period before injection with physostigmine $(0.1 \mathrm{mg} / \mathrm{kg} \mathrm{IM})$. This dosage was selected after noting the maximum dosage in pilot animals that would permit responding after $30 \mathrm{~min}$ had elapsed from time of injection. The intervals between training and injection were $30 \mathrm{~min}, 1,3,7$, 14 , or 28 days $(\mathrm{N}=6$, randomly assigned); the 28-day control group $(\mathrm{N}=12)$ was injected with .05 saline solution to evaluate normal forgetting.

Thirty minutes after injection, Ss were returned to the experimental chambers and received 150 test trials. Performance on the test trials was compared with performance on the last 150 trials of training as a measure of retention.

Training and retesting was accomplished with small numbers of Ss serving on a given day to avoid the potentially biased effects of testing all animals in a single group on a particular day.

\section{RESULTS}

Inspection of Fig. 1, in which the last 150 trials of training are compared with the 150 trials of retraining, shows that no amnesia was produced for any training-injection interval or for

well-trained or partly trained discrimination tasks. On the contrary, performance improved in all experimental retraining conditions following anticholinesterase injection. Correlated $t$ tests showed that many retraining scores were significantly greater than the original training scores, as shown in Table 1.

Table 2 shows the performance of individual Ss treated with .05 saline solution 28 days after training. Ten of 12 animals show a decrement in performance 28 days after training for the partly trained discrimination. The well-trained discrimination produced no such decrement, as Fig. 1 shows. In the 28-day experimental group, four of six Ss show improvement in discrimination performance following physostigmine injection. Thus, a habit partly learned in original training and apparently forgotten after 28 days elapse seems facilitated following physostigmine injection.

\section{DISCUSSION}

The procedure of providing an easier discrimination (color) with additional training trials creates a condition that would seem ideal for testing Deutsch's prediction that a better learned discrimination should suffer amnesia to a greater extent than a more poorly learned discrimination (Deutsch \& Lutzky, 1967). The discriminations in the present experiment were so arranged that the color discrimination was presented in a 2:1 trial
Table 2

Performance on Partly Trained Discrimination Following a 28-Day Interval from Original Training

\begin{tabular}{|c|c|c|c|c|c|}
\hline \multicolumn{3}{|c|}{$\begin{array}{c}\text { Experimental Group (Physostigmine) } \\
\text { Mean Percent Correct }\end{array}$} & \multicolumn{3}{|c|}{$\begin{array}{l}\text { Control Group (Saline) } \\
\text { Mean Percent Correct }\end{array}$} \\
\hline $\begin{array}{l}\text { Sub- } \\
\text { ject }\end{array}$ & $\begin{array}{l}\text { Before } \\
\text { Injection }\end{array}$ & $\begin{array}{c}\text { After } \\
\text { Injection }\end{array}$ & $\begin{array}{c}\text { Sub- } \\
\text { ject }\end{array}$ & $\begin{array}{l}\text { Before } \\
\text { Injection }\end{array}$ & $\begin{array}{c}\text { After } \\
\text { Injection }\end{array}$ \\
\hline $\begin{array}{c}1 \\
2 \\
3 \\
4 \\
5 \\
6 \\
\text { Mean }\end{array}$ & $\begin{array}{l}58 \\
68 \\
68 \\
72 \\
70 \\
58 \\
65.7\end{array}$ & $\begin{array}{l}78 \\
84 \\
86 \\
58^{*} \\
62^{*} \\
80 \\
74.7\end{array}$ & $\begin{array}{c}1 \\
2 \\
3 \\
4 \\
5 \\
6 \\
7 \\
8 \\
9 \\
10 \\
11 \\
12 \\
\text { Mean }\end{array}$ & $\begin{array}{l}70 \\
68 \\
70 \\
60 \\
80 \\
56 \\
60 \\
54 \\
72 \\
68 \\
66 \\
58 \\
65.2\end{array}$ & $\begin{array}{l}56^{*} \\
60^{*} \\
60^{*} \\
52^{*} \\
54^{*} \\
56^{*} \\
92 \\
56 \\
72^{*} \\
58^{*} \\
62^{*} \\
56^{*} \\
61.2\end{array}$ \\
\hline
\end{tabular}

*Denotes Ss showing no improvement after injection. ratio to the line-tilt discrimination: this was done so that, in a single day, the desired accuracy levels might be achieved for each type of discrimination ( $90 \%$ for color. $60 \%$ for line-tilt).

The reaction to the drug's administration seemed rather marked in all birds, and there was a $30-\mathrm{min}$ response suppression noted for the $0.1 \mathrm{mg} / \mathrm{kg}$ dosage in pilot animals [for doses up to $0.2 \mathrm{mg} / \mathrm{kg}$. suppression lasted from 1 to $4 \mathrm{~h}$ (Vaillant. 1964)]. Therefore, the explanation for the failure to produce amnesia is not clear; it is certain that physostigmine passes the pigeon blood-brain barrier.

The explanation may lie in species-specific characteristics of the memory function or in the task itself that is appetitive rather than shock motivated. as in the Deutsch and Leibowitz study. Amnesia, however, has recently been produced by anticholinesterase (DFP) in a task involving appetitive reward (Wiener \& Deutsch, 1968). Amnesia has also been found for rats in an appetitive study using physostigmine (Deutsch \& Wiener, 1968).

Deutsch's synaptic-conductance memory theory would predict that an older forgotten habit should be restored by anticholinesterase injection (Deutsch \& Leibowitz, 1966; Wiener \& Deutsch, 1968). It seems likely that an enhancement in recall of a partly learned discrimination has occurred in this experiment, giving partial support to Deutsch's explanation.

The failure to find amnesia in the pigeon seems to suggest that the synaptic-conductance memory theory may be restricted to memory in certain species. The nature of the task employed was found to have little effect in rats (Biederman, 1970); the learning levels obtained for the more-trained discrimination and the levels obtained in the earlier rat experiments are quite comparable. The effects of physostigmine injection seems about the same between rats and pigeons for the dosages selected, as measured by duration of response suppression. Physostigmine, however, may be more systemically toxic to the pigeon than to the rat, making it impossible to raise levels of anticholinesterase sufficiently to affect memory without side effects that would make it impossible for the bird to perform. Comparative investigations are required to account for the lack of anticholinesterase-induced amnesia in the pigeon and to test the generality of the theory suggested by Deutsch.

\section{REFERENCES}

BIEDERMAN, G. B. Stimulus function in simartaneous discrimination. Journal of the Experimental Analysis of Behavior, 1968, 11, 459-463. 
BILDERMAN, (i, B. Iorgetting of an operant response: lhysostigmine-produced amnesia in rats as a function of time of injection. Quarterly Journal of Experinental Psychology, 1970. in press.

DEUTSCH, J. A., HAMBURG, M. D.. \& DAHL, $H$. Anticholinesterase-induced amnesia and its temporal aspects. Science, 1966, 151, $221-223$.

DEUTSCH, J. A., \& LEIBOWITZ, S. F. Amnesia or reversal of forgetting by anticholinesterase, depending simply on time of injection. Science, 1966, 153, 1017-1018.

DEUTSCH, J. A., \& LUTZKY, H. Memory enhancement of anticholinesterase as a function of initial learning. Nature, 1967, 213, 742 .

DEUTSCH, J. A., \& WIENER, N. Effect of reinforcement and non-reinforcement on anticholinesterase-induced amnesia. Paper presented at American Psychological Association, 1968.

HAMBURG, M. D. Retrograde amnesia produced by intraperitoneal injection of physostigmine. Science, 1967, 156, 973-974.

VAlLLANT, G. E. Antagonism between physostigmine and atropine on the behavior of the pigcon. Archiv fur Pharmakologie und Ixpcrimentelle Pathologic, 1964, 248, 406-416.

VAILLANT, G. E. A comparison of antagonists of physostigmine-induced suppression of behavior. Journal of Pharmacology \& Experimental Therapeutics, 1967, 157 , 636-648.

WIENER, N., \& DEUTSCH, J. A. Temporal aspects of anticholinergic- and anticholinesterase-induced amnesia for an appetitive habit. Journal of Comparative \& Physiological Psychology, 1968, 66, 613-617.

\section{Strain differences in morphine-withdrawal-induced aggression in rats*}

\section{LOWELL A. BORGEN, J. H. KHALSA, WILLIAM T. KING, and W. MARVIN DAVIS University of Mississippi School of Pharmacy, University, Miss. 38677}

Male rats (housed six/cage) of three strains-Sprague-Dawley, Wistar, and Long-Evans-were given IP injections of morphine sulfate in dosages increasing over a 15-day period to a terminal dose of $405 \mathrm{mg} / \mathrm{kg} /$ day. Groups of six from each strain received saline control injections. Approximately $50 \mathrm{~h}$ after the last injection, significant increases in fighting behavior were observed in the Long-Evans and Wistar strains, the Long-Evans rats showing the most aggression. The fighting continued for about $40 \mathrm{~h}$ and then subsided to control levels. The Sprague-Dawley rats receiving morphine showed no significant increase in aggressiveness over placebo-injected animals.

Several investigations have shown that the withdrawal of morphine from physically dependent rats leads to the occurrence of fighting behavior in male Sprague-Dawley rats (Boshka, Weisman, \& Thor, 1966: Thor \& Teel, 1968) and Long.Evans rats (Thor, Hoats, \& Thor, 1970). These authors found that the fighting behavior began about 60 to $75 \mathrm{~h}$ after withdrawal from morphine, continued for 50 to $60 \mathrm{~h}$, then subsided to negligible levels. The present study was intended in part to replicate these previous studies and also to determine whether or not the occurrence of this response might

*This work was supported by USPHS Grant MH 11295-04. differ between the three most commonly used strains-the Sprague-Dawley, Wistar, and Long-Evans rats.

\section{SUBJECTS}

Thirty-six male rats of each of the three strains were used. ${ }^{1}$ The Ss were 47.57 days of age and weighed $220-280 \mathrm{~g}$ at the start of the experiments. They were housed in groups of six, with four groups of each strain being experimentals and two groups serving as controls. The cages measured $13 \frac{1}{2}$ in. wide $\times 22$ in. deep $\times 9 \frac{1}{2}$ in. high. Food and water were available ad lib throughout the experiment. Animals were ear-notched for identification and assigned randomly to groups. Prior to and throughout the experiment, the animals were maintained on a schedule of 16 h day
(0600 to 2200) and $8 \mathrm{~h}$ night. The observation rooms were illuminated by a 60-W red light at night to facilitate observation during the withdrawal period.

\section{PROCEDURE}

Experimental animals of each strain were injected with morphine sulfate over a 15-day period, starting with $15 \mathrm{mg} / \mathrm{kg} /$ day and increasing to a terminal dose of $405 \mathrm{mg} / \mathrm{kg} /$ day. All injections were made intraperitoneally, with equal doses being given at 6 a.m., 3 p.m., and 10 p.m. Drug solutions were prepared on the basis of weight of the sulfate salt, using $0.9 \% \mathrm{NaCl}$ in water as the vehicle. Placebo injections were of $0.9 \% \mathrm{NaCl}$ solution alone. A constant injection volume of $1 \mathrm{ml}$ solution $/ 200 \mathrm{~g}$ body weight was used throughout.

After the 15-day injection period, the Ss were observed for 15 -min periods every $2 \mathrm{~h}$ for 6 consecutive days. Six groups of rats (two of each strain) were observed at one time. An aggressive response was recorded only when at least two Ss assumed an upright fighting posture facing each other, and a biting attack with vocalization occurred. Experience revealed that true fighting behavior was easily distinguishable from playful "rough-housing," mounting, or grooming, although occasionally these behaviors would precipitate an actual biting attack by another animal. Because of the unique character of the fighting response, only one $\mathrm{O}$ was needed to watch the six cages during the 15 -min observation periods.

\section{RESULTS}

The cumulative fighting responses of all three strains of experimental and control animals are presented in Fig. 1. From the response curves it can be seen that the control groups from all strains displayed about the same amount of aggression over the 144-h observation period $(47,57$, and 71 responses). Curiously, the Sprague-Dawley morphine groups displayed only 50 aggressive responses during the withdrawal period. In contrast, the morphine-treated Wistar groups emitted 165 fighting responses, while the Long-Evans morphine groups showed some 460 aggressive episodes during the same interval. Figure 1 also shows that the bulk of the aggressive responses made by the Long-Evans and Wistar Ss occurred between 50 and $90 \mathrm{~h}$ after the last morphine injection.

During the withdrawal period two other behaviors indicative of an abstinence syndrome in the rat were noted. The first was a frequent shaking of the entire body, earlier described by other investigators as a "wet dog shake," and observed to be a concomitant of morphine withdrawal in 